Jorge A. Ferreira

Patrik R. Lennartsson

Mohammad J. Taherzadeh

Swedish Centre for Resource Recovery, University of Borås, Borås, Sweden
Research Article

\section{Production of ethanol and biomass from thin stillage by Neurospora intermedia: A pilot study for process diversification}

Dry mill ethanol processes produce ethanol and animal feed from whole grains, where the wastewater after the distillation and separation of solid materials is called "thin stillage." In this work, similar production of ethanol $(3.5 \mathrm{~g} / \mathrm{L})$ and biomass $(5 \mathrm{~g} / \mathrm{L})$ from thin stillage was obtained during batch cultivation of the edible fungus Neurospora intermedia in a $2-\mathrm{m}$ high airlift reactor and bubble column. The fungal biomass, containing $50 \% \mathrm{w} / \mathrm{w}$ protein and $12 \% \mathrm{w} / \mathrm{w}$ lipids, was rich in essential amino acids and omega- 3 and -6 fatty acids. In a continuous mode of fermentation, dilution rates of up to $0.2 \mathrm{~h}^{-1}$ could be applied without cell washout in the bubble column at $0.5 \mathrm{vvm}$. At $0.1 \mathrm{~h}^{-1}$, around $5 \mathrm{~g} / \mathrm{L}$ of ethanol and $4 \mathrm{~g} / \mathrm{L}$ of biomass containing ca. $50 \% \mathrm{w} / \mathrm{w}$ protein were produced. The fungus was able to assimilate saccharides in the liquid fraction as well as sugar backbones such as xylan and arabinan in the solid fraction. The inclusion of the current process could potentially lead to the production of $11000 \mathrm{~m}^{3}$ of ethanol (5.5\% improvement vs. normal industrial process) and around 6300 tons of high-quality biomass for animal feed at a typical facility producing $200000 \mathrm{~m}^{3}$ ethanol per year.

Keywords: Biomass / Bubble column / Continuous cultivation / Ethanol / Neurospora intermedia

Received: October 21, 2014; revised: May 18, 2015; accepted: July 1, 2015

DOI: $10.1002 / \mathrm{elsc} .201400213$

\section{Introduction}

The process of ethanol production from sugar- and starch-based materials is well developed at industrial scale. Brazil and United States dominate the worldwide production of ethanol, using mostly sugarcane and corn as feedstock, respectively. Beyond ethanol, animal feed nutrients commonly known as distillers dried grains with solubles (DDGS) are also produced during the process when grains (e.g. corn and wheat) are the substrates. The ethanol sector has produced ca. 86 million tons of ethanol and 68 million tons of DDGS in 2011 [1,2]. However, fluctuations on the price of the feedstock and produced products together with the energy-intensive character of the process might impose constraints to its overtime feasibility [3]. Accordingly, research towards process improvement and diversification has been carried out mostly via valorization of thin stillage. Thin stillage corresponds to the liquid fraction after whole stillage centrifugation (distillation leftovers), 15\% of which is normally recycled

Correspondence: Prof. Mohammad J. Taherzadeh (Mohammad.Taherzadeh@hb.se), Swedish Centre for Resource Recovery, University of Borås, Allégatan 1, 50190 Borås, Sweden

Abbreviations: AIM, alkali-insoluble material; DDGS, distillers dried grains with solubles; NREL, National Renewable Energy Laboratory as backset water, while the remaining goes through a series of evaporations. The resulting condensate is also sent back to the process, whereas the concentrated syrup is normally dried together with the centrifuged solids to give rise to the DDGS [4]. Therefore, the processing steps leading to the production of DDGS are responsible for a large fraction of the overall process energy requirements [3]. The production of a variety of products including ethanol, cell-oil, feed nutrients, biogas, and eicosapentaenoic acid has been investigated using thin stillage as cultivation medium [5]. In addition to the production of new products, the employed microorganisms reduce the solid content of the thin stillage. Therefore, the viscosity of the medium is lowered, which facilitates the series of evaporations and the following drying process. More thin stillage could also be used as backset (lowering the load on the evaporators and driers) and the overall process energy consumption would be reduced [6].

Filamentous fungi have been an important contributor to the global economy via production of a plethora of important products including antibiotics, enzymes, organic acids, human/animal food products among many others [7]. Particularly, in the context of production of biomass for feed applications, filamentous fungi possess an important advantage over, e.g. yeasts, since they can be easily separated from the fermentation broth without requiring a centrifugation step. Both zygomycetes and ascomycetes filamentous fungi have previously been investigated 


\section{Engineering}

www.els-journal.com in Life Sciences

Figure 1. Proposed inclusion of $N$. intermedia in the overall industrial process of ethanol production for production of biomass and ethanol from thin stillage [6], boxes highlighted in gray.

for production of ethanol and protein-rich biomass from mostly wheat-based thin stillage, where the ascomycete Neurospora intermedia was found to be the best ethanol producer [5]. This fungus is traditionally used for preparation of oncom, an indigenous Indonesian food, so that it can be classified as generally regarded as safe (GRAS), which is a great advantage if the fungal biomass is produced for animal or human consumption [8]. While Neurospora crassa is genetically as well studied as Saccharomyces cerevisiae or Escherichia coli, biotechnological research studies using $N$. intermedia are scarce in the literature. With its inclusion in the established industrial process, the biomass would join DDGS as animal feed nutrients, while the extra ethanol produced could be sent back to the process with the condensate, as it is already done at industrial scale [6] (Fig. 1). However, the cultivation of filamentous fungi in bioreactors can be troublesome due to its filamentous growth. If stirred-tank reactors are used, the fungal filaments have the tendency to entangle with the inner parts, such as baffles and impellers, leading to suboptimal mass and energy transfer rates. Airlift reactors and bubble columns have been alternatively developed and better process performances have been reported. Their main difference is the absence of inner parts, e.g. baffles and impellers being the medium mixed by the supplied air [9]. The aeration rate greatly influences fungal growth, metabolite production, and assimilation of medium nutrients. For instance, higher aeration gives rise to higher biomass and lower ethanol productions, while assimilation of xylose is not possible under anaerobic conditions [6].

The process of ethanol and biomass production from thin stillage with $N$. intermedia would represent a partial inclusion in the established industrial process of ethanol production from grains. Therefore, after previous bench-scale experiments [5], the present work tries to provide further insights into the process but at a reactor scale. Those include the influence of the supplied air, reactor design, and cultivation mode on the production of ethanol and biomass and the removal of solids from the thin stillage. First, the influence of the aeration rate was studied in a 2-m high airlift reactor. The same reactor was further simplified into a bubble column after removal of the internal-loop tube for comparison purposes at the condition where the highest amount of ethanol was obtained. The cultivation was further studied under a continuous mode in the bubble column where different dilution rates were applied. In all the research steps, special focus was on ethanol and biomass production as well as the final characteristics of the thin stillage after biomass harvesting. To the best of our knowledge, this work reports for the first time, a continuous process in bubble column using thin stillage as cultivation medium and $N$. intermedia as the catalyst.

\section{Materials and methods}

\subsection{Microorganism}

The ascomycete N. intermedia CBS 131.92 (Centraalbureau voor Schimmelcultures, The Netherlands) was used throughout this study. Strain maintenance and preparation of spore solutions were done according to Ferreira et al. [5]. Spore number was determined by using a counting chamber.

\subsection{Thin stillage}

Thin stillage used in this work was provided by Lantmännen Agroetanol (Norrköping, Sweden), an ethanol production facility mostly based on wheat grains. The two spaced in time $1 \mathrm{~m}^{3}$ thin stillage batches were stored in $230 \mathrm{~L}$ barrels at $4^{\circ} \mathrm{C}$ prior to use. Before cultivation, the thin stillage was sterilized at $121^{\circ} \mathrm{C}$ for $30 \mathrm{~min}$ in an autoclave (Systec, Germany).

\subsection{Cultivation in bioreactor}

Cultivations at different aeration rates, namely $0.5,1.0,1.5$, and $2 \mathrm{vvm}$ (air volume per culture volume per minute) were randomly carried out in a $2 \mathrm{~m}$ high, $15 \mathrm{~cm}$ diameter airlift reactor with $26 \mathrm{~L}$ total volume of the internal-loop tube reactor model (Bioengineering, Switzerland). The reactor was sterilized in situ with an injection of steam $\left(121^{\circ} \mathrm{C}, 30 \mathrm{~min}\right)$. Twenty liters of sterilized thin stillage was supplemented with $50 \mu \mathrm{L} / \mathrm{L}$ antifoam silicone Snapsil FD10 (VWR International, USA) and adjusted to $\mathrm{pH} 5.5$ with $10 \mathrm{M} \mathrm{NaOH}$. A 24 h inoculum containing $8.8 \pm 0.9 \mathrm{~g} / \mathrm{L}$ biomass dry weight (average value determined from measurements in triplicate) was prepared in three 1-L Erlenmeyer flasks containing $0.1 \mathrm{~L}$ sterilized thin stillage adjusted to $\mathrm{pH} 5.5$ with $10 \mathrm{M} \mathrm{NaOH}$. The inoculum was prepared via incubation in a water bath set at $35^{\circ} \mathrm{C}$ and shaking at $125 \mathrm{rpm}$. The spore concentration was $8.7( \pm 1.6) \times 10^{8}$ spores/L. The cultivation temperature in airlift was maintained at $35 \pm 0.4^{\circ} \mathrm{C}$. Cultivation was followed by taking $0.25 \mathrm{~L}$ samples every $12 \mathrm{~h}$ for a period of $48 \mathrm{~h}$. The thin stillage was poured through a sieve to 


\section{Engineering}

www.els-journal.com

in Life Sciences recover the biomass, and stored at $-20^{\circ} \mathrm{C}$; the harvested biomass was extensively washed with continuous flow of distilled water in order to remove most of the remaining thin stillage solids until a clear effluent was obtained. For comparative purposes, the reactor was transformed in a bubble column by removing the internal-loop tube. The cultivation was carried out as described earlier at the aeration rate of $0.5 \mathrm{vvm}$.

Continuous cultivation was also carried out in the bubble column reactor at $0.5 \mathrm{vvm}$. Three dilution rates, namely 0.1 , 0.15 , and $0.2 \mathrm{~h}^{-1}$, were sequentially applied after 1 -day batch cultivation. The sterilized thin stillage was adjusted to $\mathrm{pH} 5.0$ 5.5 with $10 \mathrm{M} \mathrm{NaOH}$ and supplied using the reactor-coupled peristaltic pump. Cultivation conditions, thin stillage storage, and biomass harvesting were done as described earlier except that samples of $1 \mathrm{~L}$ volume were taken. Four $20 \mathrm{~L}$ volumes were replaced at each dilution rate. All batch and continuous cultivations were done in duplicate.

\subsection{Cultivation in shake flasks}

Neurospora intermedia was cultivated in semisynthetic medium containing either $5 \mathrm{~g} / \mathrm{L}$ acetic acid (Sharlau Chemie), L- $(+)$ arabinose (Sigma-Aldrich), D-(+)-galactose (Acrös organics), D(-)-glucose (Fisher Chemical), glycerol (Sharlau Chemie), DLlactic acid (Acrös organics), D(+)-mannose (Fluka), or $10 \mathrm{~g} / \mathrm{L}$ $\mathrm{D}(+)$-xylose (Sigma-Aldrich). The ascomycete was also cultivated in a mixture of these carbon sources containing (in $\mathrm{g} / \mathrm{L}$ ): acetic acid 1.0, lactic acid, and glycerol 10, and the remaining carbon sources 2 . The medium was supplemented with yeast extract (ratio of carbon source:yeast extract of four), salts, and trace metals according to Millati et al. [10]. The $\mathrm{pH}$ of sugarcontaining and acid-containing media was adjusted to 5.5 with 1 or $10 \mathrm{M} \mathrm{NaOH}$, respectively, prior to sterilization for $20 \mathrm{~min}$ in an autoclave (Systec). Cultivations were carried out in $250-\mathrm{mL}$ Erlenmeyer flasks containing $50 \mathrm{~mL}$ of medium shaking at $125 \mathrm{rpm}$ using a water bath set at $35^{\circ} \mathrm{C}$ for $42 \mathrm{~h}$. The spore concentration was $2.3 \times 10^{8}$ spores/L. At the end of the cultivation, biomass was harvested using a sieve, except for that grown in acetic acid, arabinose, and lactic acid-containing medium, which was recovered by vacuum filtration, and washed extensively with distilled water. All cultivations were performed in duplicate.

\subsection{Analytical methods}

The harvested biomass, reported as biomass dry weight in gram per liter, was dried until constant weight in an oven for $24 \mathrm{~h}$ at $70^{\circ} \mathrm{C}$. The protein content of the biomass and thin stillage reported as crude protein and Kjeldahl nitrogen, respectively, was determined according to the Kjeldahl method using block digestion and steam distillation. The equipment included an InKjel $\mathrm{P}$ digestor and a behrotest ${ }^{\circledR} \mathrm{S} 1$ distiller (behr Labor-Technik, Germany). Digestion was carried out by adding $20 \mathrm{~mL}$ of $98 \%$ $\mathrm{H}_{2} \mathrm{SO}_{4}$, antifoam, and KT1 tablets (Thompson \& Capper Ltd, $\mathrm{UK})$ to $0.4 \pm 0.0 \mathrm{~g}$ material for a total duration of $100 \mathrm{~min}$ at $100 \%$ power (of which 10 min were for heating up the system). Digestion was followed by neutralization of the digested solution with $32 \% \mathrm{NaOH}$ and distillation for $5 \mathrm{~min}$. The distillation vapor
Table 1. Characteristics of the thin stillage used in batch and continuous culture of $N$. intermedia

\begin{tabular}{|c|c|c|}
\hline Parameter & Batch $^{\text {a) }}$ & Continuous $^{\mathrm{b})}$ \\
\hline $\mathrm{pH}$ & $3.5 \pm 0.0$ & $4.3 \pm 0.0$ \\
\hline Kjeldahl nitrogen $(\mathrm{g} / \mathrm{L})$ & $4.4 \pm 0.2$ & $5.3 \pm 0.1$ \\
\hline Total solids $(\mathrm{g} / \mathrm{L})$ & $77.5 \pm 3.4$ & $90.1 \pm 3.3$ \\
\hline Suspended solids (g/L) & $26.0 \pm 0.9$ & $30.5 \pm 0.2$ \\
\hline Ash (g/L) & $10.3 \pm 0.5$ & $8.8 \pm 0.4$ \\
\hline \multicolumn{3}{|l|}{ Dissolved monomers } \\
\hline Arabinose $(\mathrm{g} / \mathrm{L})$ & $0.6 \pm 0.1$ & $1.0 \pm 0.1$ \\
\hline Galactose (g/L) & $\mathrm{ND}^{\mathrm{c})}$ & $0.7 \pm 0.1$ \\
\hline Glucose (g/L) & $0.5 \pm 0.1$ & $0.9 \pm 0.1$ \\
\hline Xylose (g/L) & $0.6 \pm 0.2$ & $0.7 \pm 0.1$ \\
\hline Glycerol (g/L) & $7.6 \pm 0.5$ & $9.9 \pm 0.1$ \\
\hline Acetic acid (g/L) & $0.9 \pm 0.1$ & $0.3 \pm 0.1$ \\
\hline Ethanol (g/L) & $1.7 \pm 0.2$ & $0.4 \pm 0.1$ \\
\hline Lactic acid $(\mathrm{g} / \mathrm{L})$ & $11.6 \pm 0.9$ & $2.8 \pm 0.1$ \\
\hline \multicolumn{3}{|l|}{ Dissolved saccharides ${ }^{\mathrm{d}}$ ) } \\
\hline Arabinose (g/L) & $4.4 \pm 0.2$ & $6.2 \pm 0.0$ \\
\hline Galactose (g/L) & $1.6 \pm 0.2$ & $1.7 \pm 0.0$ \\
\hline Glucose (g/L) & $9.8 \pm 0.7$ & $16.4 \pm 0.3$ \\
\hline Mannose (g/L) & $1.4 \pm 0.2$ & $1.7 \pm 0.2$ \\
\hline Xylose (g/L) & $6.1 \pm 0.4$ & $6.8 \pm 0.1$ \\
\hline \multicolumn{3}{|l|}{ Solid fraction } \\
\hline Arabinan (mg/L) & $242 \pm 140$ & $374 \pm 46$ \\
\hline Galactan (mg/L) & $175 \pm 42$ & $193 \pm 32$ \\
\hline Glucan (mg/L) & $3182 \pm 383$ & $4553 \pm 531$ \\
\hline Mannan (mg/L) & $488 \pm 234$ & $979 \pm 83$ \\
\hline Xylan (mg/L) & $907 \pm 419$ & $920 \pm 129$ \\
\hline
\end{tabular}

a) Thin stillage used for batch cultivation.

b) Thin stillage used for continuous cultivation.

c) Not detected.

d) Dissolved monomers included.

was trapped in $50 \mathrm{~mL}$ of $4 \% \mathrm{H}_{3} \mathrm{BO}_{4}$. Final titration was carried out with $0.1 \mathrm{M}$ of $\mathrm{HCl}$ until $\mathrm{pH} 4.6$. A factor of 6.25 was used to calculate the crude protein content. Determination of amino acid composition of the biomass and thin stillage (SS-EN ISO 13903:2005) and fatty acid composition of the biomass (Karlshamn's analysis methods $\mathrm{Nr} 2.5 .1$ and $\mathrm{Nr} 2.5 .2$ ) was performed by Eurofins (Lidköping, Sweden). The biomass cell wall fraction reported as alkali-insoluble material (AIM) was determined according to Zamani and Taherzadeh [11].

The total solids, suspended solids, and their structural composition were determined according to the National Renewable Energy Laboratory (NREL) methods, including "preparation of samples for compositional analysis" [12], "determination of structural carbohydrates and lignin in biomass" [13], and "determination of total solids in biomass and total dissolved solids in liquid process samples" [14]. The dissolved saccharides in thin stillage were determined according to the NREL method including "determination of sugars, by-products, and degradation products in liquid fraction process samples" [15].

The liquid fractions from thin stillage and NREL protocolresulting samples were analyzed using HPLC (Waters 2695, USA) according to Ferreira et al. [5]. In addition to xylose and arabinose, the lead (II)-based column was also used for analysis of glucose, galactose, and mannose. All samples for HPLC analysis 


\section{Engineering}

www.els-journal.com

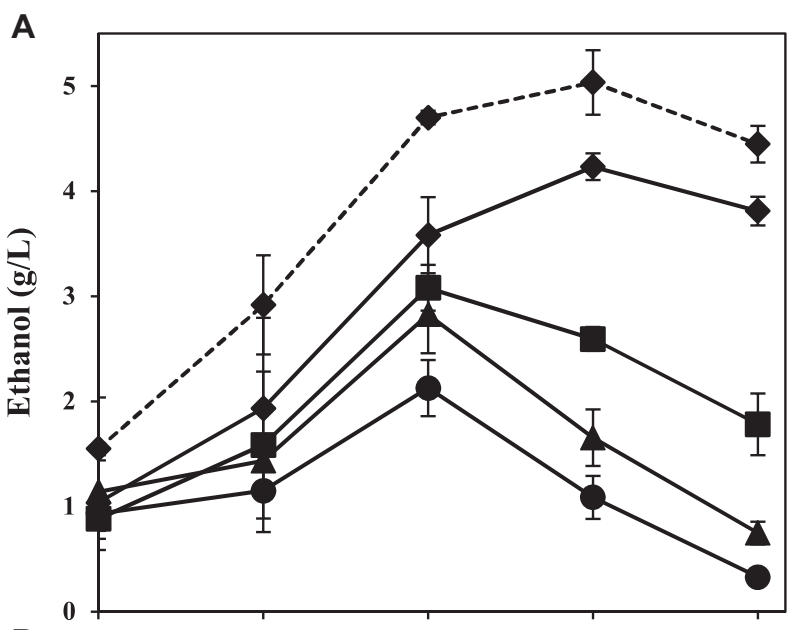

B

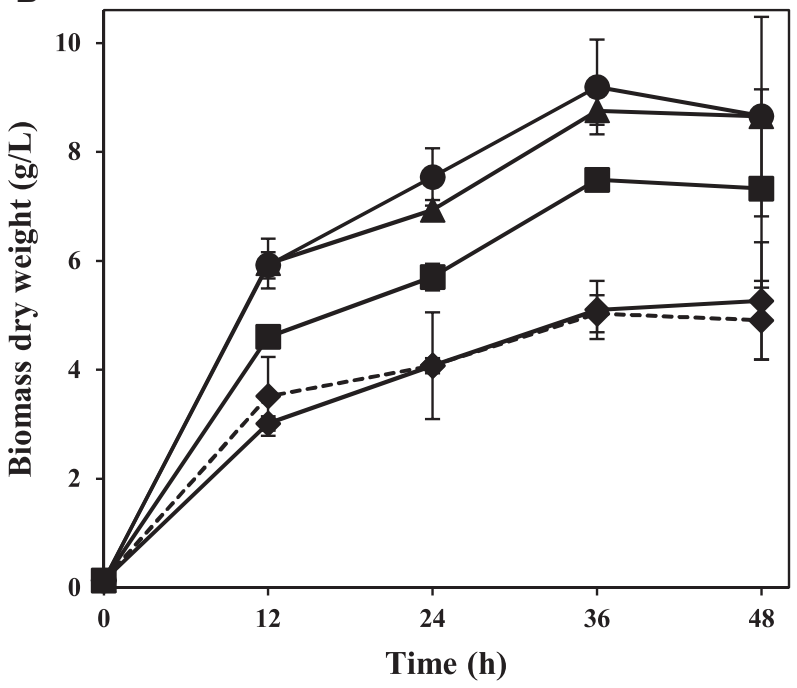

Figure 2. (A) Ethanol and (B) biomass dry weight profiles obtained during $48 \mathrm{~h}$ of cultivation of $N$. intermedia in airlift (straight lines) and bubble column (dashed line) at $0.5(\bullet), 1(\boldsymbol{\square}), 1.5(\mathbf{\Delta})$, and $2 \mathrm{vvm}(\bullet)$. All conditions were tested in duplicate and all error bars represent two SDs.

were centrifuged for $10 \mathrm{~min}$ at $10000 \times \mathrm{g}$, and the supernatant was stored frozen at $-20^{\circ} \mathrm{C}$.

\section{Results}

\subsection{Ethanol and biomass production from thin stillage}

\subsubsection{Aeration rate effect}

The effect of the aeration rate on the production of ethanol and biomass from thin stillage was studied in a $2-\mathrm{m}$ high airlift reactor (Fig. 2A and B). A clear trend was observed where higher the aeration rate applied, the lower ethanol and the higher biomass production achieved and vice-versa. The highest amount of produced ethanol of around $3 \mathrm{~g} / \mathrm{L}$ was achieved at $0.5 \mathrm{vvm}$ while the highest amount of produced biomass of around $9 \mathrm{~g} / \mathrm{L}$ was achieved at $2 \mathrm{vvm}$. It was also observed that at aeration rates higher than $0.5 \mathrm{vvm}$, the ethanol concentration decreased after $24 \mathrm{~h}$ of cultivation. The biomass crude protein slightly decreased during cultivation at all tested aeration rates applied, where crude protein ranges of $48-53 \% \mathrm{w} / \mathrm{w}$ were found.

\subsubsection{Reactor design effect}

For comparative purposes, the airlift reactor was simplified into a bubble column by removing the internal-loop tube and the cultivation was performed at $0.5 \mathrm{vvm}$. As shown in Fig. $2 \mathrm{~A}$ and $\mathrm{B}$ (dashed line) the ethanol and biomass production profiles between airlift and bubble column were similar. The highest ethanol production and production rate were $3.5 \pm 0.2 \mathrm{~g} / \mathrm{L}$ after $36 \mathrm{~h}$ and $131 \pm 20 \mathrm{mg} / \mathrm{L} / \mathrm{h}$ after $24 \mathrm{~h}$ of cultivation, respectively. The highest biomass production was $5.0 \pm 0.3 \mathrm{~g} / \mathrm{L}$ after $36 \mathrm{~h}$ of cultivation. Considering that using a bubble column reactor instead of an airlift represents cost savings, a more detailed study on the composition of the biomass harvested after $48 \mathrm{~h}$ of cultivation was carried out and compared to that of the DDGS (Table 2). All nine essential amino acids to humans were present in N. intermedia biomass and accounted to $40 \%$ of its amino acid composition. The most striking differences between DDGS and fungal biomass were the amounts of glutamic acid, lysine, and proline. The lipid content of the biomass was mainly composed of linoleic acid $(47.6 \pm 0.7 \%)$, palmitic acid $(20.5 \pm 1.5 \%)$, oleic acid $(15.3 \pm 0.4 \%), \alpha$-linoleic acid $(4.6 \pm 0.1 \%)$, and stearic acid (3.8 $\pm 0.2 \%$; Table 2$)$. The cell wall fraction as AIM of $N$. intermedia showed roughly a $60 \%$ increase during cultivation; it composed $18.9 \pm 0.4 \% \mathrm{w} / \mathrm{w}$ and $30.3 \pm 1.6 \% \mathrm{w} / \mathrm{w}$ of the biomass after 12 and $48 \mathrm{~h}$ of cultivation, respectively. A maximum of $1.5 \pm 0.1 \mathrm{~g} / \mathrm{L}$ of AIM was obtained at the end of the cultivation. The ash content of the biomass was $5.1 \pm 0.1 \% \mathrm{w} / \mathrm{w}$ at the end of the cultivation.

\subsubsection{Cultivation mode effect}

Under continuous cultivation in the bubble column at $0.5 \mathrm{vvm}$, dilution rates up to $0.2 \mathrm{~h}^{-1}$ could be applied without cell washout (Fig. 4A). The production of ethanol decreased at higher dilution rates; the highest ethanol production of $5.1 \pm 1.0 \mathrm{~g} / \mathrm{L}$ was achieved at $0.1 \mathrm{~h}^{-1}$ (Fig. 3A). However, the ethanol production rate showed an inverse trend where the highest value of $778 \pm 59 \mathrm{mg} / \mathrm{L} / \mathrm{h}$ was achieved at a dilution rate of $0.2 \mathrm{~h}^{-1}$, which was $27 \%$ higher than that at a dilution rate of $0.1 \mathrm{~h}^{-1}$ (Fig. 3B). The trend for biomass production was similar to that for ethanol where the highest value of $3.6 \pm 0.9 \mathrm{~g} / \mathrm{L}$ was achieved at a dilution rate of $0.1 \mathrm{~h}^{-1}$ (Fig. $4 \mathrm{~A}$ ). The highest biomass production rates were similar at 0.1 and $0.15 \mathrm{~h}^{-1}(363 \pm 93$ and $366 \pm 61 \mathrm{mg} / \mathrm{L} / \mathrm{h}$, respectively) and decreased when the highest dilution rate was applied (Fig. 4B). The crude protein of the biomass after $66 \mathrm{~h}$ of cultivation (end of the first dilution rate) was analyzed and found to be $50.1 \pm 3.8 \% \mathrm{~g} / \mathrm{g}$ on a dry basis.

\subsection{Thin stillage}

The two commercial $1 \mathrm{~m}^{3}$ thin stillage batches used during this study were composed of around $60 \% \mathrm{w} / \mathrm{w}$ total solids of potential carbon sources and of around 6\% w/w total solids of nitrogen. The main differences between the two batches were the contents 


\section{Engineering}

www.els-journal.com

Table 2. Protein and lipid composition of industrial DDGS and N. intermedia biomass obtained from a 48-h cultivation in bubble column reactor at $0.5 \mathrm{vvm}$

\begin{tabular}{|c|c|c|c|c|c|}
\hline Component (mg/g) & DDGS & N. intermedia & Component (mg/g) & DDGS & N. intermedia \\
\hline \multicolumn{3}{|c|}{ Protein content and amino acid profile } & \multicolumn{3}{|c|}{ Lipid content and fatty acid profile } \\
\hline Crude protein & $514 \pm 13$ & $529 \pm 65$ & Lipid & $77 \pm 2$ & $116 \pm 11$ \\
\hline Alanine & $20.2 \pm 0.5$ & $32 \pm 4$ & C 14:0 & $\mathrm{ND}^{\mathrm{a})}$ & $<1$ \\
\hline Ammonia & $17.2 \pm 0.4$ & $13 \pm 3$ & C 15:0 & ND & $<1$ \\
\hline Arginine & $23.1 \pm 0.6$ & $29 \pm 8$ & C 16:0 & ND & $24 \pm 5$ \\
\hline Aspartic & $28.6 \pm 0.7$ & $39 \pm 9$ & C 16:1n-7 & ND & $<1$ \\
\hline Cysteine & $11.1 \pm 0.3$ & $6 \pm 1$ & C 17:0 & ND & $<1$ \\
\hline Glutamic acid & $143.2 \pm 3.6$ & $52 \pm 10$ & C 17:1 n-7 & ND & $<1$ \\
\hline Glycine & $19.3 \pm 0.5$ & $22 \pm 6$ & C 18:0 & ND & $4 \pm 0$ \\
\hline Histidine $^{\mathrm{b})}$ & $11.2 \pm 0.3$ & $12 \pm 3$ & C 18:1n-9 & ND & $18 \pm 1$ \\
\hline Isoleucine $\mathrm{e}^{\mathrm{b})}$ & $21.8 \pm 0.6$ & $21 \pm 7$ & C $18: 2 n-6$ & ND & $55 \pm 4$ \\
\hline Leucine $^{\mathrm{b})}$ & $37.7 \pm 1.0$ & $32 \pm 10$ & C $18: 3 n-3$ & ND & $5 \pm 0$ \\
\hline Lysine $e^{b)}$ & $15.7 \pm 0.4$ & $33 \pm 9$ & C 20:0 & ND & $<1$ \\
\hline Metionine $^{b}$ ) & $8.4 \pm 0.2$ & $8 \pm 3$ & C 20:1n-9 & ND & $<1$ \\
\hline Ornitine & $0.3 \pm 0.0$ & $6 \pm 1$ & C 20:2n-6 & ND & $<1$ \\
\hline Proline & $46.0 \pm 1.2$ & $19 \pm 3$ & C 22:0 & ND & $<1$ \\
\hline Phenylalaline $^{\mathrm{b})}$ & $25.2 \pm 0.6$ & $18 \pm 6$ & C 24:0 & ND & $<1$ \\
\hline Serine & $26.2 \pm 0.7$ & $21 \pm 5$ & C 24:1 n-9 & ND & $<1$ \\
\hline Threonine $^{\mathrm{b})}$ & $16.8 \pm 0.4$ & $21 \pm 5$ & & & \\
\hline Tryptophan ${ }^{\text {b) }}$ & $5.7 \pm 0.1$ & $7 \pm 2$ & & & \\
\hline Tyrosine & $18.1 \pm 0.5$ & $15 \pm 4$ & & & \\
\hline Valine $^{b)}$ & $26.1 \pm 0.7$ & $27 \pm 9$ & & & \\
\hline
\end{tabular}

a) Not determined.

b) Essential amino acids to humans.

of lactic acid, glucose, and arabinose in the liquid fraction and glucan and mannan in the solid fraction (Table 1).

During batch cultivation, either in the airlift at different aeration rates or in the bubble column, the acetic acid present in the thin stillage was consumed after $12 \mathrm{~h}$ of cultivation, glycerol and lactic acid concentrations remained constant and the total solids were reduced by $12-17 \% \mathrm{w} / \mathrm{v}(10-15 \mathrm{~g} / \mathrm{L})$. At the end of cultivation in the bubble column, the thin stillage $\mathrm{pH}$ was $6.2 \pm 0.1$ and its ash content had been reduced by $31.9 \pm 13.1 \% \mathrm{w} / \mathrm{v}$.

The analysis of the dissolved saccharides and sugar polymers in the solid fraction was carried out for bubble column batch and continuous cultivations and the findings are depicted in Fig. 5. During batch cultivation in the bubble column, the concentration of arabinose-, glucose- and xylose-based saccharides has been reduced by more than $70 \%$. The total amount of carbon sources reduced in the liquid fraction was $16.0 \pm 0.1 \mathrm{~g} / \mathrm{L}$ (Fig. 5A). Under continuous cultivation the reduction of dissolved glucose- and xylose-based saccharides at the stable phase decreased gradually at higher dilution rates (Fig. 5B); at $0.1 \mathrm{~h}^{-1}$ their reduction was $14.7 \pm 1.6 \mathrm{~g} / \mathrm{L}$ while that of arabinose, galactose, and mannose was $<0.5 \mathrm{~g} / \mathrm{L}$. Neurospora intermedia could also assimilate sugar polymers where a reduction range of 57 $91 \%(2.5 \pm 0.2 \mathrm{~g} / \mathrm{L})$ was achieved during batch cultivation. Under continuous cultivation, the reduction of xylan in the suspended solids decreased gradually at higher dilutions rates whereas such a clear trend was not clearly observed for other sugar backbones present in the suspended solids (Fig. 5C and D). Total reduction amount was $2.4 \pm 0.2 \mathrm{~g} / \mathrm{L}$ at $0.1 \mathrm{~h}^{-1}$. During continuous cultivation at a dilution rate $0.1 \mathrm{~h}^{-1}$, the reduction of measured sugars both in liquid and solid fraction $(18.1 \pm 1.4 \mathrm{~g} / \mathrm{L})$ was comparable to that of total solids $(16.9 \pm 3.8 \mathrm{~g} / \mathrm{L})$. Thus, at this dilution rate, the yield of ethanol was $303 \pm 9.5 \mathrm{mg} / \mathrm{g}$ of reduced solids.

\section{Discussion}

\subsection{Ethanol and biomass production from thin stillage}

\subsubsection{Aeration rate effect}

At the reactor scale, the supplied air plays a crucial role on the fungal cultivation performance since it influences the fungal growth, metabolite production, and assimilation of medium nutrients [9]. The supplied air was found to influence the production of ethanol and biomass in a 2-m high airlift reactor, where a clear trade-off between the production of ethanol and biomass when varying the aeration rate was found. Although the condition that achieved the highest ethanol production was chosen for further studies, economical evaluations are needed in order to ascertain which aeration rate would be more positive for the process. Moreover, it is worth noting that the dissolved oxygen was not monitored during this work. The dissolved oxygen would provide further insights into the oxygen uptake rate of the fungal culture and oxygen supply rate by the culture vessel, rendering its status of a key factor during process scale-up [16].

Also, due to better oxygen transfer rates achieved at reactor scale in comparison to that at bench-scale experiments with shake flasks, higher production of biomass was expected to be achieved. The maximum biomass value achieved during batch cultivation in the airlift was lower than that achieved in a previous work with shake flasks experiments with the same fungal 


\section{Engineering}

www.els-journal.com in Life Sciences
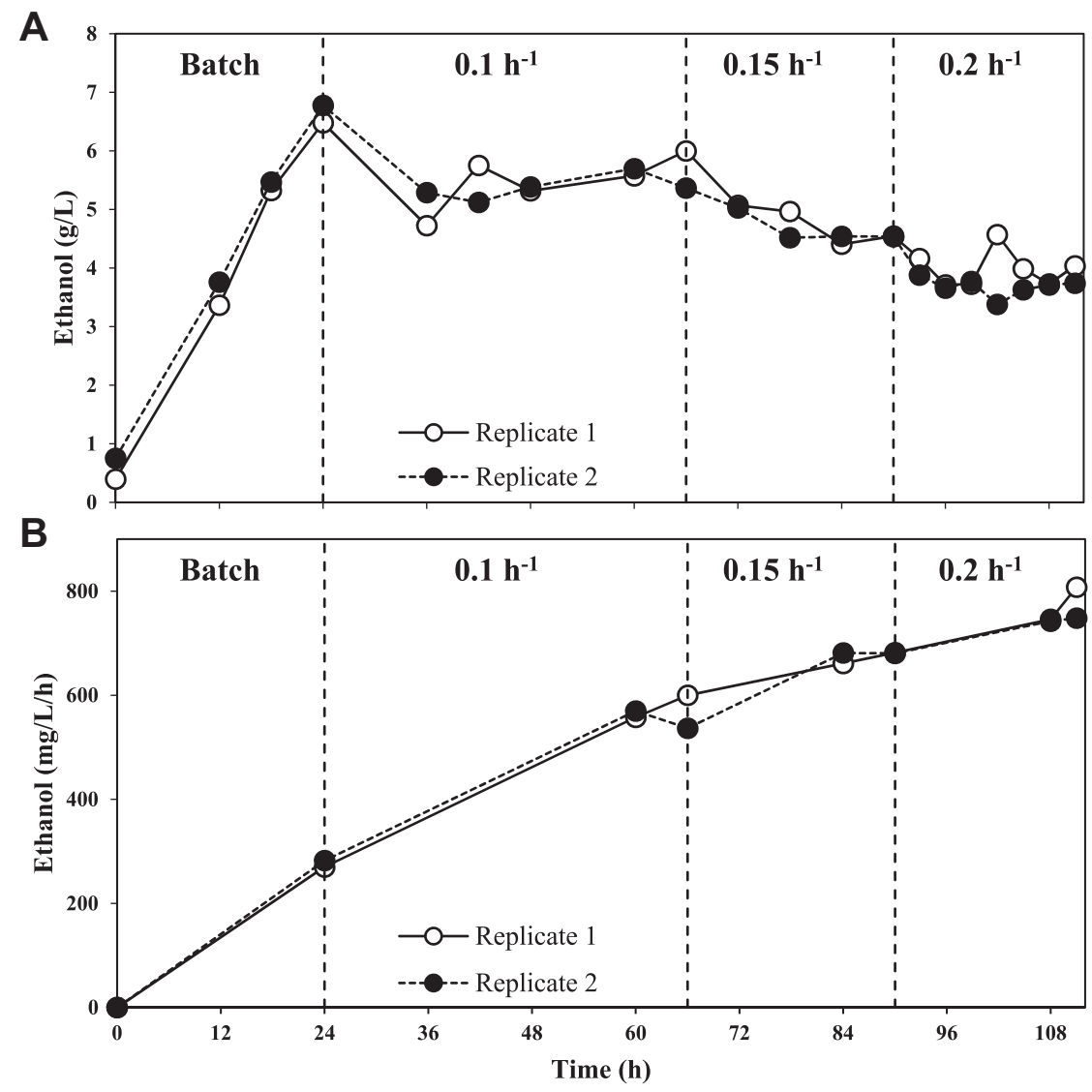

Figure 3. (A) Ethanol concentration and (B) ethanol production rate during continuous cultivation of $N$. intermedia in thin stillage at dilution rates of $0.1,0.15$, and $0.2 \mathrm{~h}^{-1}$. The cultivation was shifted to continuous mode after $24 \mathrm{~h}$ of batch cultivation.

strain [5]. The observed differences might be related to differences in the thin stillage composition used or inefficient wash stage of the biomass, since $N$. intermedia grew as massive mycelial suspensions in shake flasks [5]. In the airlift, the ascomycete grew as small clumps of decreasing size for progressively higher aeration rate. Ferreira et al. [17] have observed the effect of better oxygen transfer rates when cultivating a Rhizopus sp. in spent sulfite liquor. They achieved clear improvement in biomass production when changing from shake flasks to the airlift reactor.

\subsubsection{Reactor design effect}

Due to their growth morphology, the cultivation of filamentous fungi has been widely explored using reactors with simpler design, such as airlifts and bubble columns alternatively to the traditional stirred-tank reactors. This study shows that a simpler reactor, such as a bubble column can be used for production of ethanol and biomass with the same performance as an airlift, which at a starting point represents cost savings. Airlift reactors have been developed as an alternative to bubble column reactors. The internal-loop tube of the airlift promotes a different mixing pattern that has been shown to lead to comparatively better mass and oxygen transfer rates [18]. However, such effect was not observed in this study. Perhaps, such effect would be seen if the process had been compared at higher aeration rates, using other reactor size and/or experimental setup.

\subsubsection{Cultivation mode effect}

This study also shows the possibility of setting a continuous cultivation, which means that a smaller size reactor can be used. Dilution rates up to $0.2 \mathrm{~h}^{-1}$ could be applied without cell washout. At progressively higher dilution rates namely from 0.1 to 0.15 and $0.2 \mathrm{~h}^{-1}$, the ethanol production was reduced by around $1 \mathrm{~g} / \mathrm{L}$ and the production rate increased by around $100 \mathrm{mg} / \mathrm{L} / \mathrm{h}$. As shown in Fig. 3, a threshold in production rate seems to be achieved when increasing the dilution rate from 0.1 to $0.15 \mathrm{~h}^{-1}$. However, the production rate almost doubled when setting the cultivation in a continuous instead of batch mode. The implication of using this dilution rate of $0.1 \mathrm{~h}^{-1}$ is that a reactor of $2000 \mathrm{~m}^{3}$, around four times smaller than that needed for a batch process of $36 \mathrm{~h}$, would be sufficient considering a thin stillage flow of $200 \mathrm{~m}^{3} / \mathrm{h}$. Reasonably, developing a cell-retention system for the current process would potentially have positive effects on achieving higher dilution rates and thus, much smaller reactors and less investment would be needed. In contrast to the advantageous higher productivities and reduction of the reactor size, continuous processes have contamination as the major drawback. The risk of contamination is increased due to the additional flows to and from the reactor. However, the potential loss due to contamination is usually much smaller than the gain with the productivity [19]. In this work, during continuous cultivation of $N$. intermedia in thin stillage, growth of lactic acid bacteria was detected after 72 and 36 h of cultivation for the replicates 1 and 2, respectively. However, the bacterial growth did not 


\section{Engineering}

www.els-journal.com

\section{in Life Sciences}

A

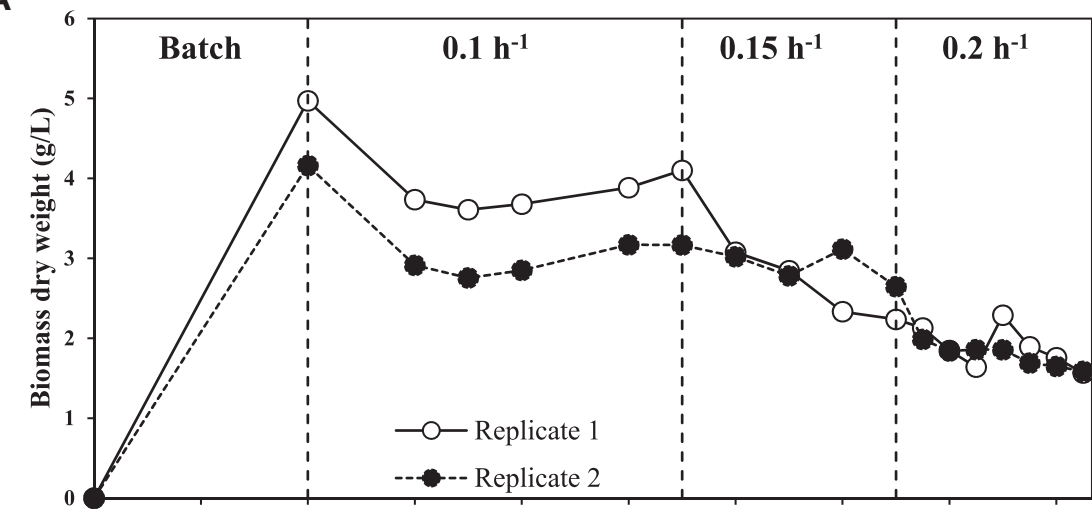

B

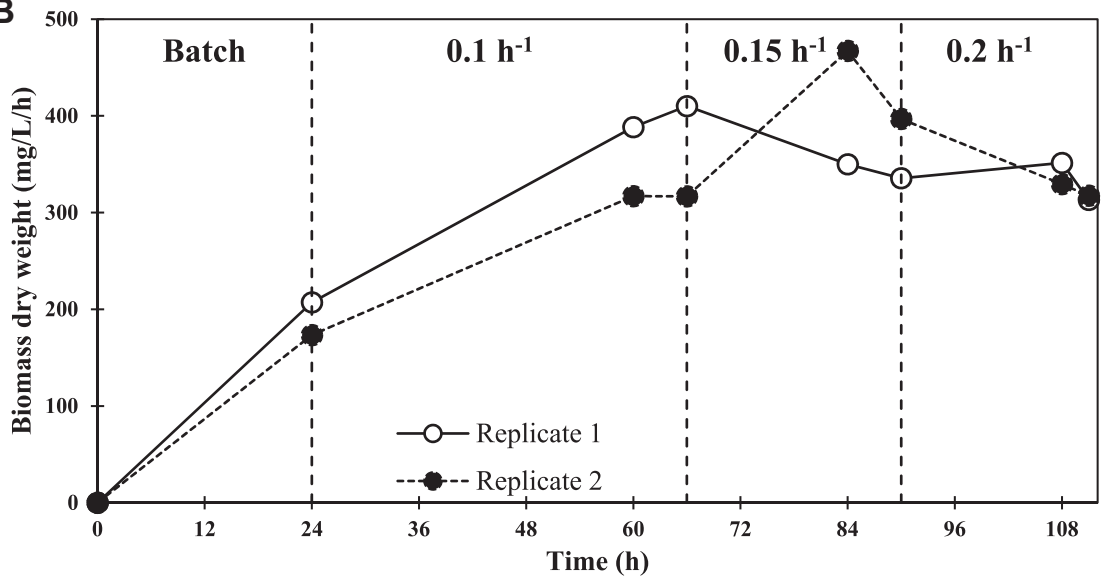

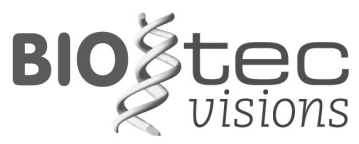

www.biotecvisions.com

Figure 4. (A) Biomass dry weight and (B) biomass production rate during continuous cultivation of $N$. intermedia in thin stillage at $0.1,0.15$, and $0.2 \mathrm{~h}^{-1}$. The cultivation was shifted to continuous mode after $24 \mathrm{~h}$ of batch cultivation.

affect the production of ethanol: As shown in Fig. 4A, there is a difference regarding biomass production (around $1 \mathrm{~g} / \mathrm{L}$ ) among replicates between 24 and $66 \mathrm{~h}$ of cultivation, which was not observed for the ethanol production (Fig. 3A). Moreover, lactic acid bacteria did not take over the cultivation; the lactic acid concentration in the medium, which increased from 3 to $5 \mathrm{~g} / \mathrm{L}$ with bacterial contamination, remained constant at all dilution rates applied. The yield of ethanol obtained was $303 \pm 9.5 \mathrm{mg} / \mathrm{g}$ of reduced solids at a dilution rate of $0.1 \mathrm{~h}^{-1}$. To the best of our knowledge, the only work on production of ethanol from thin stillage was by Gonzalez et al. [20]. The authors have reported an ethanol yield of $0.42 \mathrm{~g} / \mathrm{g}$ based on consumed glycerol, maltose, and glucose by E. coli.

\subsection{Production of ethanol and biomass from thin stillage — implications}

The treatment and use of thin stillage is crucial in order to achieve cost-effective and environmentally friendly ethanol production facilities. In dry mill processes, typically 6-7 $\mathrm{L}$ of thin stillage is produced per liter of ethanol [21]. Therefore, thin stillage is available in large quantities and can be used for production of other value-added products considering its relevant amount of nitrogen and carbon sources [22].

The inclusion of the current process in the established industrial ethanol plant could lead to the production of two value-added products, namely ethanol and biomass for feed. Taking into account the present industrial setup, it is hypothesized that such process inclusion would not trigger high capital investments. For instance, all needed apparatus for the distillation of the ethanol produced by N. intermedia is already available at the industrial plant. The alcohol would follow the normal stream of condensate after the series of evaporations back to the normal process and then to the distillation column as it is done nowadays at the industrial scale (Fig. 1).

The produced biomass could be dried together with the solids from the stillage centrifugation and the syrup from the series of evaporations (Fig. 1). The use of filamentous fungi is also attractive, since the separation of the biomass from the medium is easier when compared with that for yeast or bacterial cells since a centrifugation step is not needed. In view of its protein, amino acid, lipid, and fatty acid composition as well as its comparable profile of amino acids with that of DDGS, $N$. intermedia biomass is a potential source of high-quality nutrients for feed application. The ascomycete lipid fraction was to a large extent composed of polyunsaturated fatty acids (52.3 \pm $0.8 \%$ ) of which $47.8 \pm 0.7 \% \mathrm{w} / \mathrm{w}$ were omega- 6 fatty acids and $4.6 \pm 0.1 \% \mathrm{w} / \mathrm{w}$ were omega- 3 fatty acids. Those polyunsaturated fatty acids are considered essential to human diet [23]. Moreover, the cell wall of Ascomycetes has chitin as main component and although the presence of native chitosan has not been reported for these fungi, the extraction of chitosan has previously been carried out $[24,25]$. Chitosan applications have steadily been 
A
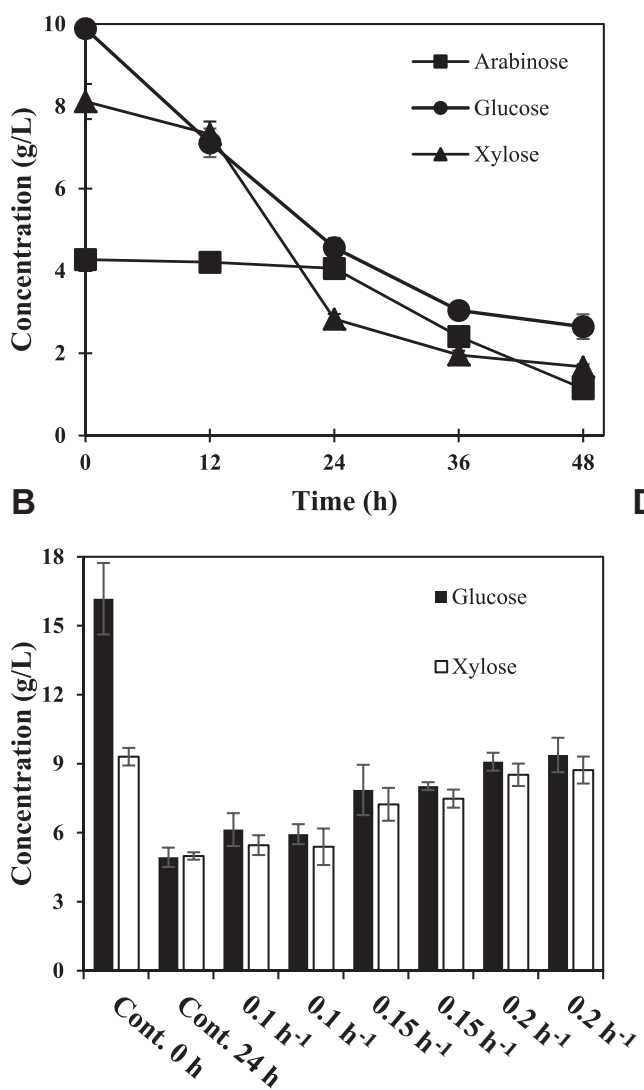

C
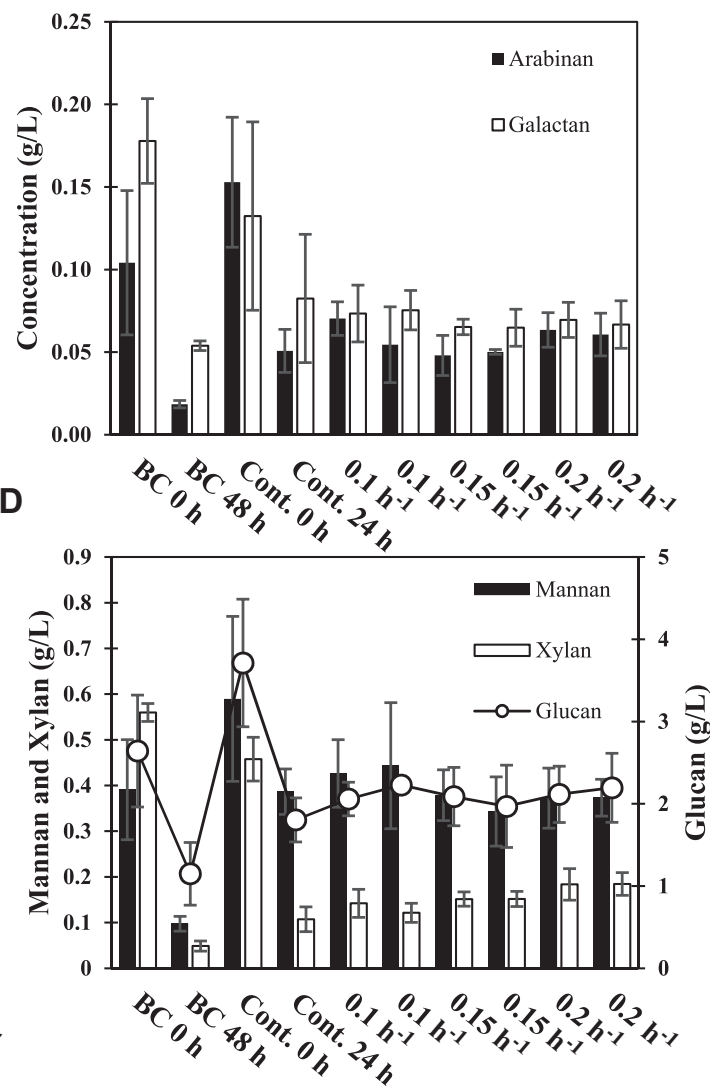

Figure 5. Profiles of ( $A$ and $B$ ) dissolved saccharides in the liquid fraction and ( $C$ and $D$ ) sugar polymers in the solid fraction of thin stillage during batch and continuous cultivation of N. intermedia in the bubble column. Error bars represent two SDs. "BC" stands for the batch process in the bubble column, "Cont." stands for the continuous cultivation, and "Cont. $0 \mathrm{~h}$ " and "Cont. $24 \mathrm{~h}$ " represent the $24 \mathrm{~h}$ of batch cultivation preceding the continuous cultivation. The graph (A) includes the sugar profiles during batch cultivation in the bubble column.

increasing, e.g. in the health sector [26]. Therefore, the extra biomass produced via inclusion of the present process would increase and diversify the amount of animal feed nutrients of the ethanol industry.

In addition to the production of ethanol and fungal biomass, the inclusion of $N$. intermedia in the industrial ethanol process can have a positive impact on thin stillage evaporation and drying steps via assimilation of organic matter. Continuous cultivation of $N$. intermedia at a dilution rate of $0.1 \mathrm{~h}^{-1}$ led to the reduction of $18 \% \mathrm{w} / \mathrm{v}$ of thin stillage solids including dissolved saccharides and sugar polymers in the solid fraction. Other potential carbon sources, such as glycerol and lactic acid remained constant at all conditions tested in this work. Clearly, N. intermedia preferred carbon sources than glycerol or lactic acid. In semisynthetic medium, the ascomycete had consumed all glycerol after $42 \mathrm{~h}$ of cultivation when it was the single carbon source in the medium. However, when the fungus was cultivated in a mixture of carbon sources, glycerol started to be consumed just when all hexoses and pentose sugars were depleted. Neurospora intermedia hardly consumed lactic acid though; only $1 \mathrm{~g} / \mathrm{L}$ of lactic acid had been consumed after $42 \mathrm{~h}$ of cultivation. Beyond being converted to mainly ethanol, $\mathrm{CO}_{2}$, and biomass, the reduction of solids can have a positive impact on the energy savings of the overall production process. Removing water during the series of evaporations would be easier and so the amount of water to be removed when in the driers would be lower. Furthermore, more thin stillage could be sent back to the process lowering the load on the evaporators and driers [6].

\section{Concluding remarks}

In this work, up to $5 \mathrm{~g} / \mathrm{L}$ of ethanol and $4 \mathrm{~g} / \mathrm{L}$ of biomass were obtained during $N$. intermedia growth in thin stillage under continuous mode using a 2-m high bubble column of $26 \mathrm{~L}$ capacity. Similar results regarding maximum ethanol and biomass production were obtained when the same reactor was used as airlift or bubble column in a batch mode. Moreover, the production of ethanol and biomass was found to be intimately related to the assimilation of both dissolved saccharides and sugar polymers present in the thin stillage suspended solids. The inclusion of the present process under a continuous mode at $0.1 \mathrm{~h}^{-1}$ in a bubble column can potentially lead to the production of around $11000 \mathrm{~m}^{3}$ of ethanol (5.5\% improvement vs. the normal process) as well as 6300 tons of biomass that can be used for animal 


\section{Engineering}

www.els-journal.com

\section{in Life Sciences}

or fish feed at a facility producing $200000 \mathrm{~m}^{3}$ of ethanol per year.

\section{Practical application}

The present research can potentially have a positive impact on the overall process economics of the established industrial process of ethanol production from grains. Thin stillage, a wastewater obtained after distillation and solid separation, can be used for production of ethanol and biomass for feed using the edible filamentous fungus Neurospora intermedia. Less investment is needed since the produced ethanol can follow the normal stream towards the distillation column after the series of evaporations, which is already being done in the industry. The produced biomass can be dried in the same way as the animal feed products produced by the dry mill ethanol facilities, commonly known as DDGS (distillers dried grains with solubles). Considering the data obtained in this study, an improvement of $5.5 \%$ on ethanol production as well as the production of around 6300 tons of biomass could potentially be achieved at a facility producing $200000 \mathrm{~m}^{3}$ of ethanol per year.

The authors are grateful for the financial support by the Swedish Energy Agency. The authors also wish to acknowledge Lantmännen Agroetanol (Sweden) for their support and also providing the thin stillage used in this research work.

The authors have declared no conflict of interest.

\section{References}

[1] Martinot, E., Sawin, J., Renewables 2012 Global Status Report, REN21, Paris, France 2012.

[2] Hendrix, J. L., Sustainable agricultural practices impact on phosphate rock production. Procedia Eng. 2012, 46, 54-61.

[3] McAloon, A., Taylor, F., Yee, W., Ibsen, K. et al., Determining the Cost of Producing Ethanol from Corn Starch and Lignocellulosic Feedstocks, NREL, Colorado, USA 2000.

[4] Taherzadeh, M. J., Karimi, K., Enzyme-based hydrolysis processes for ethanol from lignocellulosic materials: A review. Bioresources 2007, 2, 707-738.

[5] Ferreira, J. A., Lennartsson, P. R., Taherzadeh, M. J., Production of ethanol and biomass from thin stillage using food-grade zygomycetes and ascomycetes filamentous fungi. Energies 2014, 7, 3872-3885.

[6] Lennartsson, P. R., Erlandsson, P., Taherzadeh, M. J., Integration of the first and second generation bioethanol processes and the importance of by-products. Bioresource Technol. 2014, 165, 3-8.

[7] Gibbs, P.A., Growth of filamentous fungi in submerged culture: Problems and possible solutions. Crit. Rev. Biotechnol. 2000, 20, $17-48$.
[8] Sastraatmadja, D. D., Tomita, F., Kasai, T., Production of highquality oncom, a traditional Indonesian fermented food, by the inoculation with selected mold strains in the form of pure culture and solid inoculum. J. Fac. Agric. Hokkaido Univ. 2002, 70, 111-127.

[9] Ferreira, J. A., Lennartsson, P. R., Edebo, L., Taherzadeh, M. J., Zygomycetes-based biorefinery: Present status and future prospects. Bioresource Technol. 2013, 135, 523-532.

[10] Millati, R., Edebo, L., Taherzadeh, M. J., Performance of Rhizopus, Rhizomucor, and Mucor in ethanol production from glucose, xylose, and wood hydrolyzates. Enzyme Microb. Tech. 2005, 36, 294-300.

[11] Zamani, A., Taherzadeh, M., Production of low molecular weight chitosan by hot dilute sulfuric acid. Bioresources 2010, 5, 1554-1564.

[12] Hames, B., Ruiz, R., Scarlata, C., Sluiter, A. et al., Preparation of Samples for Compositional Analysis, NREL, Colorado, USA 2008.

[13] Sluiter, A., Hames, B., Ruiz, R., Scarlata, C. et al., Determination of Structural Carbohydrates and Lignin in Biomass, NREL, Colorado, USA 2011.

[14] Sluiter, A., Hames, B., Hyman, D., Payne, C. et al., Detemination of Total Solids in Biomass and Total Dissolved Solids in Liquid Process Samples, NREL, Colorado, USA 2008.

[15] Sluiter, A., Hames, B., Ruiz, R., Scarlata, C. et al., Determination of Sugars, Byproducts, and Degradation Products in Liquid Fraction Process Samples, NREL, Colorado, USA 2008.

[16] Junker, B. H., Scale-up methodologies for Escherichia coli and yeast fermentation processes. J. Biosci. Bioeng. 2004, 97, 347364.

[17] Ferreira, J. A., Lennartsson, P. R., Niklasson, C., Lundin, M. et al., Spent sulphite liquor for cultivation of an edible Rhizopus sp. Bioresources 2012, 7, 173-188.

[18] Merchuk, J. C., Siegel, M. H., Air-lift reactors in chemical and biological technology. J. Chem. Technol. Biotechnol. 1988, 41, 105-120.

[19] Hermann, T., Industrial production of amino acids by coryneform bacteria. J. Biotechnol. 2003, 104, 155-172.

[20] Gonzalez, R., Campbell, P., Wong, M., Production of ethanol from thin stillage by metabolically engineered Escherichia coli. Biotechnol. Lett. 2010, 32, 405-411.

[21] Kosikowski, F. V., Whey utilization and whey products. J. Dairy Sci. 1979, 62, 1149-1160.

[22] Siso, M. I. G., The biotechnological utilization of cheese whey: A review. Bioresource Technol. 1996, 57, 1-11.

[23] Meyer, B., Mann, N., Lewis, J., Milligan, G. et al., Dietary intakes and food sources of omega- 6 and omega-3 polyunsaturated fatty acids. Lipids 2003, 38, 391-398.

[24] Bartnicki-Garcia, S., Cell wall, chemistry, morphogenesis, and taxonomy of fungi. Annu. Rev. Microbiol. 1968, 22, 87-108.

[25] Hu, K.-J., Hu, J.-L., Ho, K.-P., Yeung, K.-W., Screening of fungi for chitosan producers, and copper adsorption capacity of fungal chitosan and chitosanaceous materials. Carbohydr. Polym. 2004, 58, 45-52.

[26] Aranaz, I., Mengibar, M., Harris, R., Panos, I. et al., Functional characterization of chitin and chitosan. Curr. Chem. Biol.2009, 3, 203-230. 